\title{
International System for Cytogenetic Nomenclature of Domestic Animals (1989)
}

The Second International Conference on Standardization of Domestic Animal Karyotypes

D. DiBerardino.' H. Hayes. ${ }^{2}$ R. Fries, 'and S. Long

Deparınent of Animal Science. Limversity of aples. Naples (ltaly).

I.N.R.A. Cytogenetic Laboratory. Jouy-en-Josas (France).

'Departnent of Animal Science, ETH. Zürich (Switzerland), and

- Department of Animal Husbandry. Universily ol Bristol. Bristol (CK) 


\section{Historical introduction (P. Popescu)}

This year is the 25th anniversary of the discovery of chromosome abnormalities in domestic animals. In 1964 Gustavsson and Rockborn reported in Sweden the lirst Robertsonian-like translocaltion incallle. the I:29 translocation, and Henrictison and Backstrom discovered the first heterozygous translocation in the pig. These two papers stimulated a renewed interest in livestock sylogenetics.

In the following years. many laboratories were established worldwide for the study of chromosome disorders in domestic animals. Considerable effort was also devoted to the accumulation and application of knowledge of the normal and abnormal chromosomes of livestock.

In the early seventies. the application of banding methods to domestic animal chromosomes produced dilferent systems of cytogenetic nomenclatture of the various species that resulted in confusion and indicalled a need for standardization. For this realson, a small group of workers convened in Reading in 1976. The objeclive wats 10 describe the G-band patterns in sulficient detail to permit the identification of individual chromosomes. The system proposed in the report of the Reading Conference was the basis for all subsequent descriptions of chromosome abnormalities and variants in domestic animals.

Since the Reading Conference. several other chromosome banding techniques were developed. The purpose of the Second Conference for Standardization of Domestic Animal Karyotypes wals to standardize karyotypes with different banding techniques. which can be used for the description of chromosome abnormalities and for gene mapping.

\section{Objectives}

The objeclives of this meeting were to update the standard karyotypes of caltle. goalt. and sheep established at the first meeting in Reading and also of the improved karyolype recommended by Long (1985) for sheep: to correlate the G-banded and R-banded karyotypes and thereby establish standard karyotypes for Rbanded chromosomes; and to establish a system of nomenclature for both band types allong with schematic representaltions.

\section{Cattle (Bos toumus)}

Coordinator: D. Di Berardino

Contributors: D. Di Berardino, M. B. Lioi. D. Matalssino. H. Hayes. R. Hediger. R. Fries. H. R. Jung. and G. Stranzinger

Received 3 November 1989: accepted 30 November 1989.

When referring to this repert in text, 11 should be cited as ISCNDA 1989. The complete citation for relerence lists is: ISCNDA (1989): International System for Cylugcnetic Nomenclature of Domestic Animals. Di Berardino D. I tayes H. Fries R. Hong S (cds). Cyrogenetic Coll Ginct 5.3:65 79 (1990).

Single. Irece copies of reprints ciat be ubtained from like Editors. Drs. H. Hayes and P. PopesLu. Laboratoire de Cytogencicique. Instilut National de la Recherchic Agronomique. 78352 Jouy-en-Josas Cedex (Franoe). Reprints can also be purchased in sets of two copies lion S. Karger AC.

ISBN 3-8055-5218-1.
The extensive inlormation at vailable on the chromosomes of caltle lacilitated general agreement on this species and all the objeclives noted above could be achieved.

The G-banded standard karyotype established at the Reading Conference was confirmed and improved with the aid of the results oblained from promelaphase chromosomes. The numbering of the chromosomes follows completely that of the Reading clatssification. A standard GTG-banded karyolype for callle is shown in lig. 1 .

Since the Q-staining method wals the lirst one used to produce band palterns on chromosomes (Hansen. 1972), a QFQ-banded karyotype lor caltle prometaphase chromosomes is included in this report (Fig. 2).

The results of the sequential GTG-RBA-banding technique applied to chromosomes of the same metaphase. developed by $\mathrm{Di}$ Berardino for caltle chromosomes (in preparaltion) made it possible to establish an unambiguous correlation between G-banded and R-banded chromosomes and to deline the standard haryotype for cattle R-banded chromosomes, Figures 3 and 4 present standard RBA-and RBG-banded karyotypes for caltle.

ldiograms were constructed for both G- and R-bands. landmarks and regions wcre defined, and bands were numbered. As far as possible. landmarks were placed in positive or negallive G-bands which constitute a distinct and recognizable element of the chromosome and which subdivide it into approximalely equal regions containing al most nine bands.

The numbering of regions and bands is balsed on the Internattional System for Human Cylogenetic Nomenclature (ISCN. 1985). In some calses. since the number of bands observed wals not always the same according to the type of banding used. it was necessary 10 divide the bands into sub-bands. For example. in the R-band paltern of chromosome 3. the three sub-bands 3., 1, 3.2. and 3.3 .3 correspond $t o$ band 33 in the G-band pattern.

The idiograms (Fig. 5) were drawn using biack and white lor all euchromatic bands. Centromeric regions are crosshatched and are numbered $\mathrm{pl} l$ and or q II. Their size is lixed arbitrarily as equal for all alutosomes. The first euchromalic band is then numbered pl 2 orgl 1 ?

These schematic representations of chromosomes correspond approximallely 10400 bands for either band type $410 \mathrm{G}$-bands. 404 R-bands ).

The G-and R-banded chromosomes of catule can be described as lollows:

Chomosome /. Four regions. 21 G-bands: two negallive central bands (31 and 33\} separated by a positive band (32): a terminal negalive band (45): a narrow dark telomerc. 21 R-bands: three prominent positive bands. two centrall (31 and 33). of ten joined. and one terminal band (45).

Chromosome ?. Four regions. $20 \mathrm{G}$-bands: lour positive bands (13. 15.22. and 24) in the proximal half of the chromosome. 1.3 and 15 sometimes fused: four positive bands $(34,36,42$, and 44$)$ in the distal half, 42 and 44 being more prominent: a negative lelomere. 20 R-bands: one prominent positive band ( 21 ) in the proximal half of the chromosome: three prominent positive bands in the distal hall (41. 43. and 45 ): 43 and 45 often joined.

Chromosme 3. Three regions. $15 \mathrm{G}$-bands; a positive subcentromeric band (12). two prominent central positive bands ( 24 and 32) separalled by a large negalive band (31). 17 R-bands; a 
Fig. 1. Standard GTG-banded caltle kiryotype. (Courlesy of D. Di Berardino.)
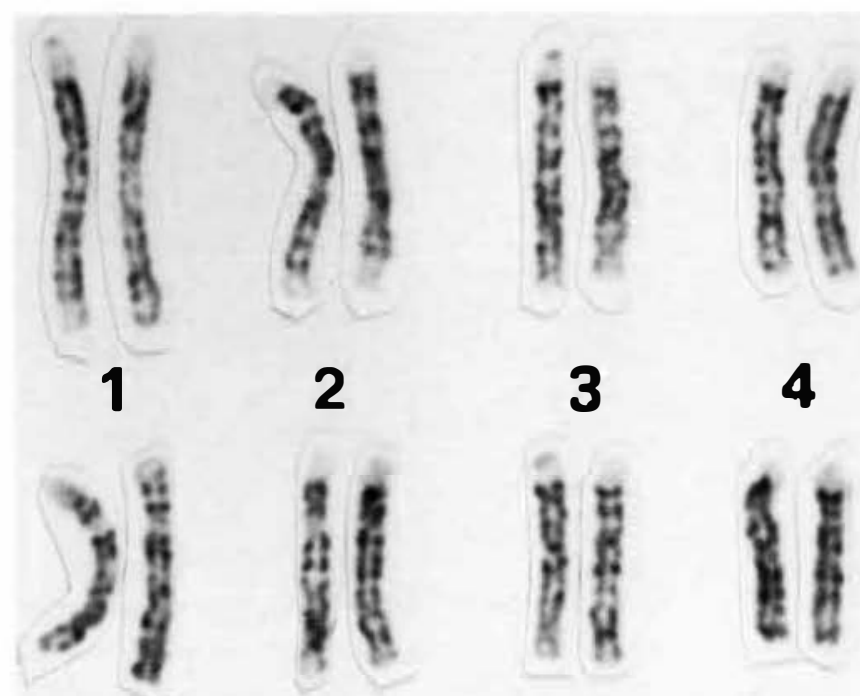

7
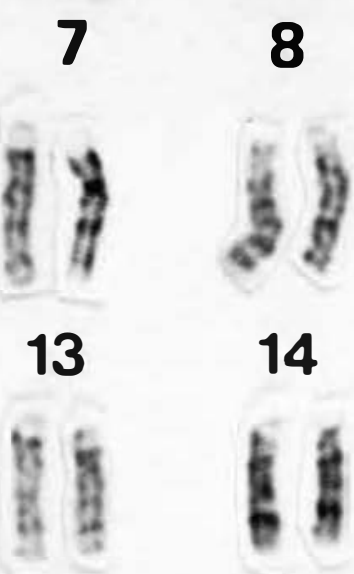

14

19

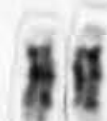

25
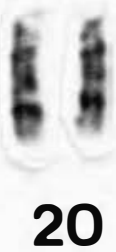

20

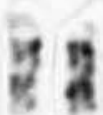

26
9

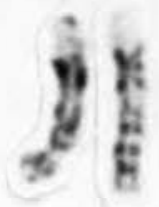

15

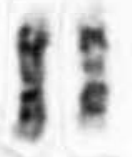

21

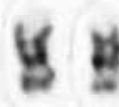

27
10

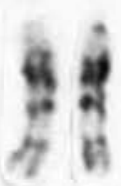

16
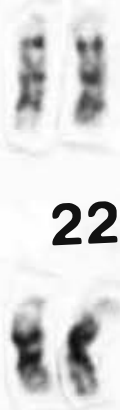

28

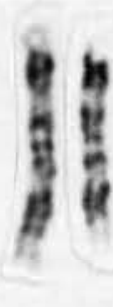

5

6

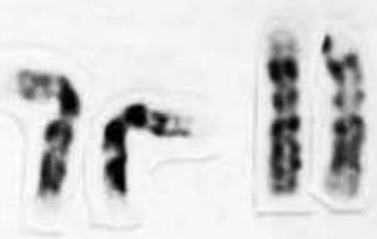

11

12
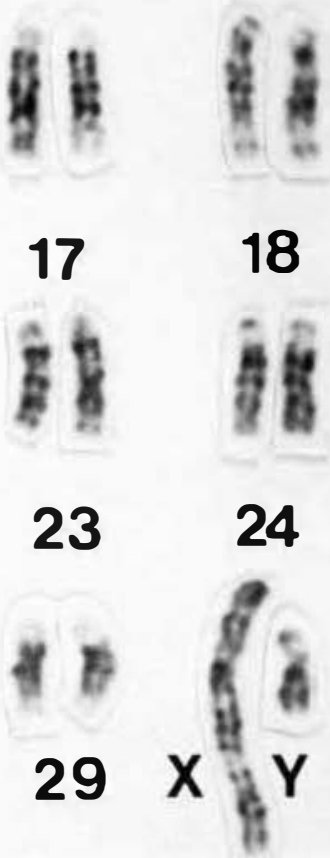

central prominent positive band (31) with two adjacent negative bands. one above (24) and one below (32. which is broader than 24).

C'hromosome t. Three regions. 19 (i-bands; four positive bands (12. 14. 16, and 18) in the proximal hall of the chromosome with at large negaltive band ( 15 ) between bands 14 and 16 ; two prominent positive bands ( 21 and 31 ) separated by an additional small positive band (23) in the distal half of the chromosome. 19 R-bands: at prominent positive band $(15)$ in the proximal hall of the chromosome: two negative bands (21 and 31 ) separated by a group of two positive bands (22 and 24) in the distal half: three positive terminal bands of ten joined.

Chromosome 5. Three regions. 15 G-bands; two broad central negative bands (21 and 31 ) separated by a group of three positive bands (22, 24. and 26) equally distributed: a negaltive telomere. 15
R-bands: three prominent positive bands: one proximal (21). one central (3l), and one terminal (35), the balter resulting from the fusion of two sub-bands.

('hromosome 6. Three regions. 17 G-bands: three positive bands (12,14, and 21) equally distributed in the proximal halif of the chromosome; the distal hall resembles that of chromosome No. 4 with (wo positive bands (23 and 31 ) separated by a small positive band (25). 17 R-bands; two prominent negative bands (21 and 31) divide the chromosome into three regions; three terminal positive bands close to each other, as in region No. 3 of chromosome No. 4.

Chromosomte 7. Two regions, 13 G-bands; two prominent positive bands: one proximal (21) and one distal (25). the latter broader than the former and containing (wo or more sub-bands; a negative telomeric band (28) not al walys visible. 13 R-bands: one large prox- 


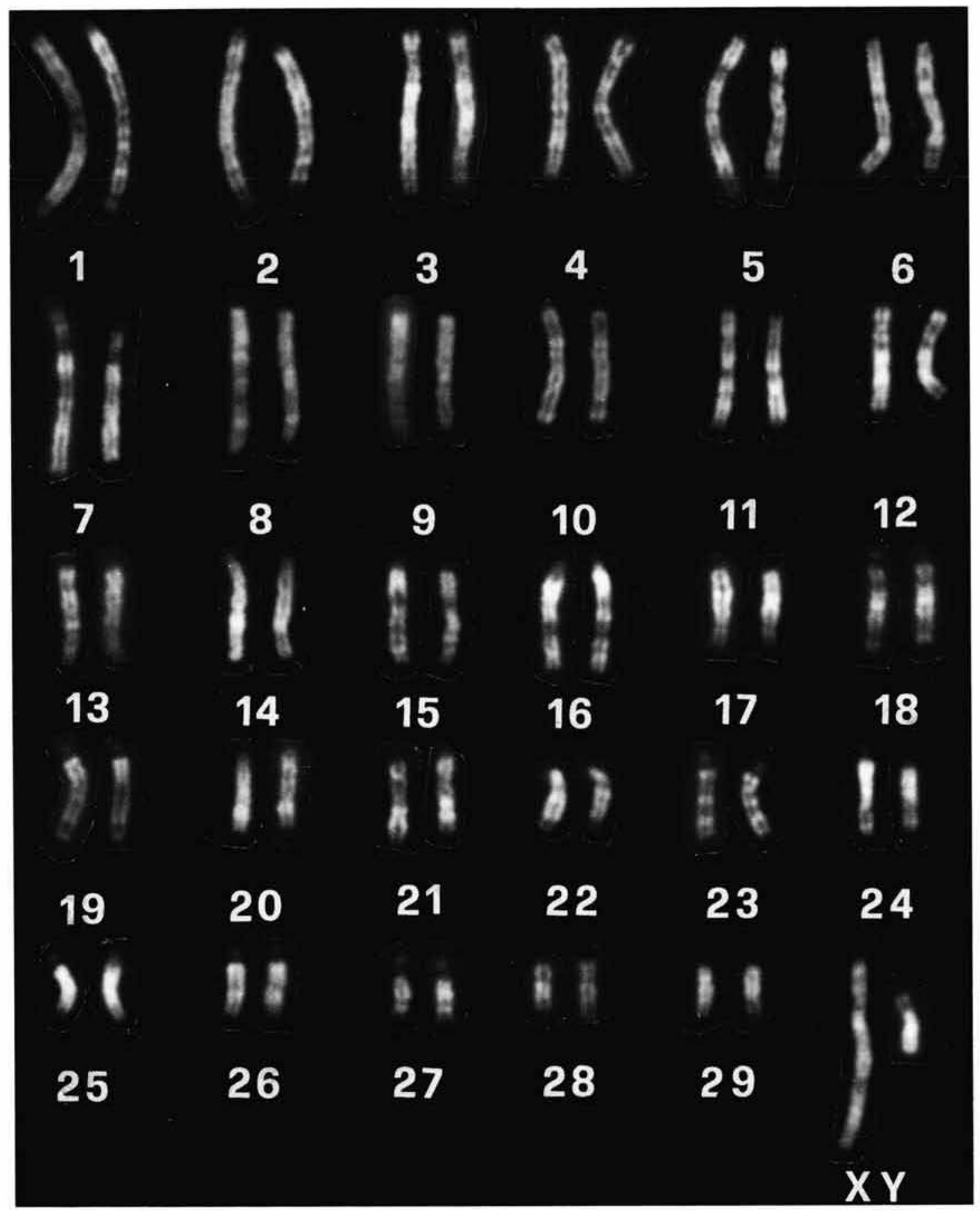

Fig. 2. Standard QFQ. banded cattle karyotype. (Courtesy of D. Di Berardino.)

imal positive band (15). two central prominent positive bands (22 and 24) followed by a large negative band (25), and two small terminal positive bands (26 and 28).

Chromosome 8. Two regions. $16 \mathrm{G}$-bands: four positive bands 112. 14, 16. and 18) separated into two groups by a large negative band $(15)$ in the proximal half of the chromosome: a prominent subterminal positive band (26), 16 R-bands: a cluster of three positive bands (21. 23, and 25) in the distal half of the chromosome followed by a negative band (26) and a subterminal positive band (27): a negative telomere.

Chromosome 9. Two regions. 17 G-bands; two proximal positive bands (12 and 14), one prominent central positive band (21). and two terminal positive bands (25 and 27). 17 R-bands; a prominent central positive band (19) followed by a broad negative band (21) and two strong positive bands (24 and 26).

Chromosome 10. Three regions. 17 G-bands; symmetrical pattern for regions No. 1 and 2: one subcentromeric positive band (12\}. four positive bands equally distributed (1 4. 21, 23, and 25): two prominent positive bands ( 31 and 33 ), a subterminal small positive band (35) in the distal part of the chromosome: a negative telomere. 19 R-bands: symmetrical pattern for regions No. 1 and 2; two positive bands ( 13 and 15 ) often joined in the proximal hall of the chromosome: a prominent subterminal positive band (34); a positive telomere. 


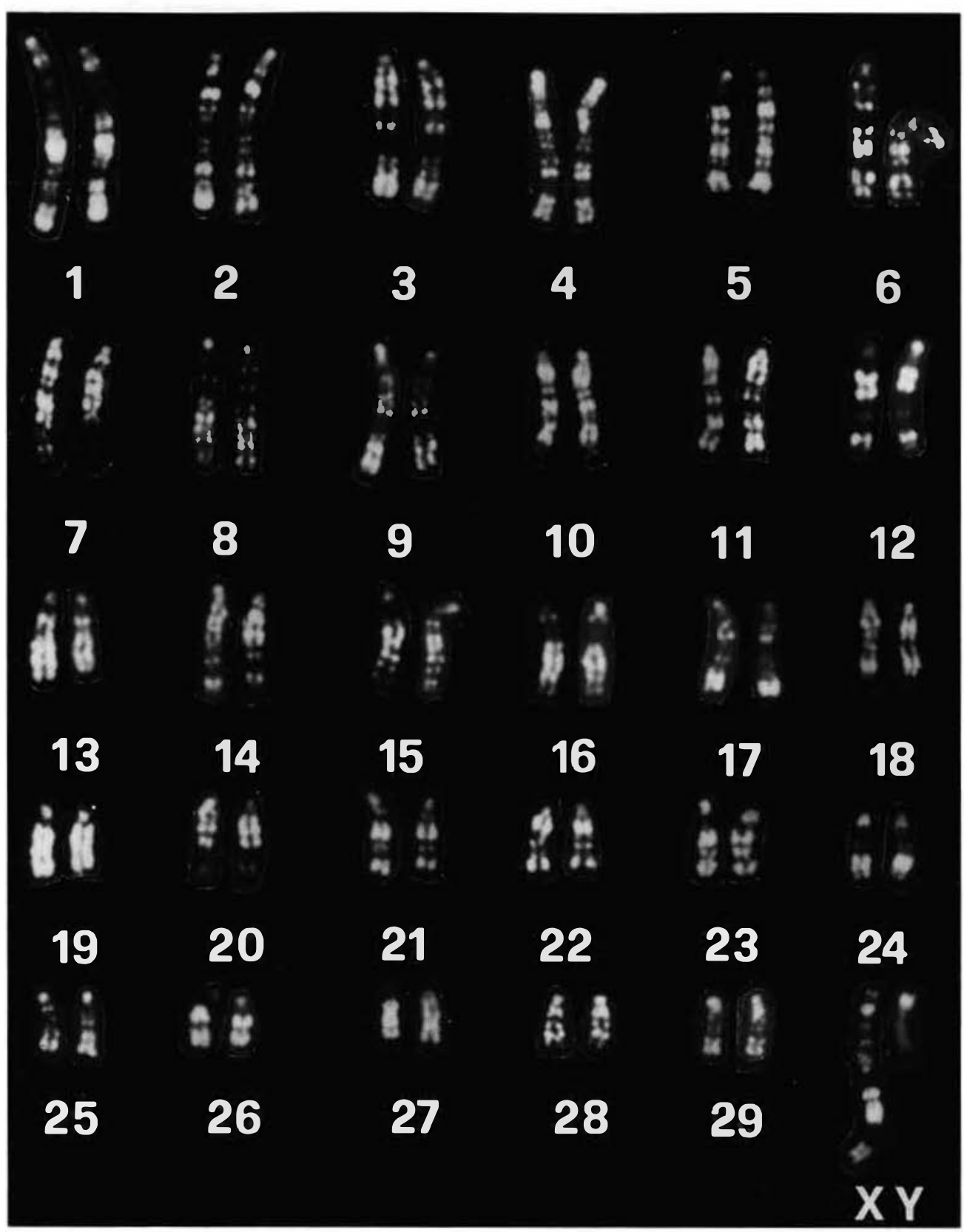

Fig. 3. Standard RBA-banded cattle kary oly pc. (Courtesy of D. Di Berardino.)

Chromosome /1. Two regions. 14 G-bands: two prominent ceniral bands (21 and 23); two positive bands $(13$ and 15$)$ in the proximal part of the chromosome and two other positive bands (25 and 27) in the distial part: a negative telomere. 16 R-bands: two broad central negative bands (2I and 23) separatted by (wo small positive bands (22.1 and 22.3): threepositive bands (1 2.14. and 16) usually joined in the proximal part of thechromosome and t wo prominent positive bands (24 and 28) in the distal part.

Chromosome 12. Two regions. II G-bands: one prominent subcentromeric band (12) and two prominent positive bands (2) and 23) in the distal hall of the chromosome. II R-bands; a negaltive subccntromeric band (12) followed by two prominent positive bands ( 13 and 15) usually joined in the proximal hall of the chromosome: two large negaltive bands (21 and 23) separated by a small positive band (22) in the distal hall: a positive telomere.

Chromesome 13. Two regions. II G-bands; a prominent subcentromeric positive band (12) followed by two positive bands ( 14 and 16 ) in the proximal hall of the chromosome: two positive bands (21 and 23) separalled by a wide negaltive band (22) in the distal hall: a negaltive telomere. I I R-bands: a large negaltive subcentromeric band (12) and a strong positive band (13) in the proximal part of the chromosome; a cluster of three strong positive bands (17.22. and 24) in the distall half.

Chromosome 14. Two regions. 15 G-bands: lour small positive bands (12. 14. 16, and 18) eyually distributed in the proximal half of the chromosome: (wo prominent positive bands (21 and 23) in the distal hall. 15 R-bands; four positive bands (1 3, 15, 17, and 19) 


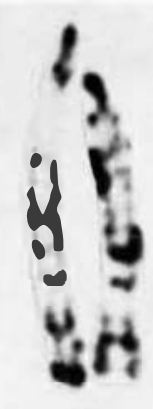

1
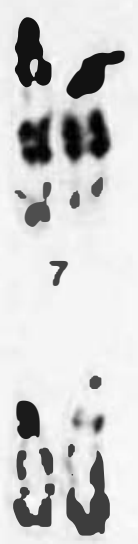

13

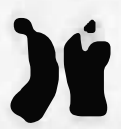

19

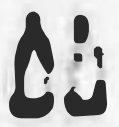

25

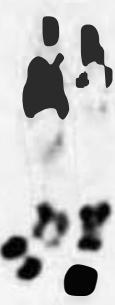

2

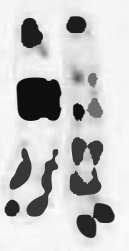

8

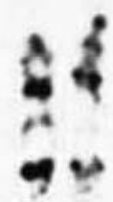

14

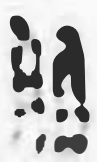

20

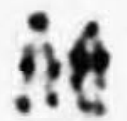

26

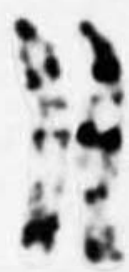

3

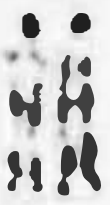

9

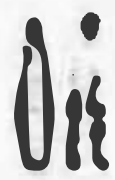

15

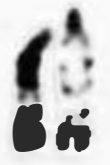

21

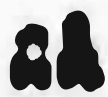

27

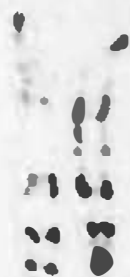

4

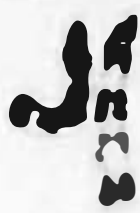

10

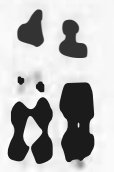

16

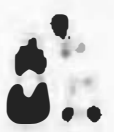

22

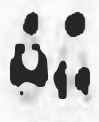

28

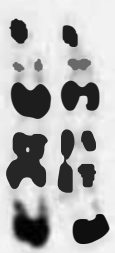

5

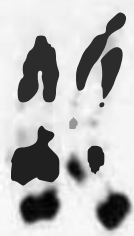

11

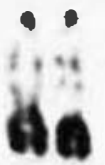

17

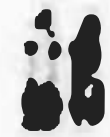

18

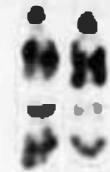

12

Fig. 4. Standard RBG-banded caltle karyotype. (Courtesy of H. Hayes.)

equally distributed in the proximal half of the chromosome: in the distal half: Iwo large negallive bands (21 and 23) separalled by a small positive band (22), and a sublcrminal positive band (24): a positive tclomerc.

Chromessume 15. Two regions. $1.3 \mathrm{G}$-bands: a prominent subcentromeric positive band (12) and a large negallive band (21) in the proximal half of the chromosome: four cqually distributed. positive bands (22. 24. 26. and 28) in the distal half: a negative telomerc. $1.3 \mathrm{~K}$-bands: three positive bands (21, 23 and 25) clustered at the center of the chromosome: I wo smaller terminal posjtive bands (27 and 29).

C'momesome 16. Two regions.12 G-bands; a subcentromeric negalive band (12) and three positive bands $(13.15$, and 17$)$ in the proximal half of the chromosome: a broad negalive band (21) and
Iwo small positive bands (22 and 24) in the distal half: a negative Iclomere. 12 R-bands; a subcentromeric positive band (12) followed by Iwo broald negalive bands (13 and 15$)$ separaled by a small positive band (14): four positive bands (16. 21. 23. and 25) usually clustered in the distal part of the chromosome.

Chromosome 17. Two regions. II G-bands: two prominent cenIral positive bands (2I and 23): a negallive telomere. II R-bands: Iwo broald central negative bands (2l and 23) followed by Iwo prominent terminal positive bands (24 and 26). usually joined.

Chromosome 18. Two regions. 11 G-bands: symmetrical palltern with three central positive bands (14, 21, and 23), a subcentromeric positive band (12) and a sublerminal positive band (25): a negative telomere. II R-bands; symmetrical pattern with al prominent proximal positive band (1.3). Iwo small positive bands 
(15 and 22) at the center of the chromosome and a prominent terminal positive band (24): a positive telomere.

(hromosome 19. Two regions. I0 G-bands; a subcentromcric positive band ( 12 ) followed by three small positive bands (14. I6. and 2I ) equally distributed: a positive telomcre. It R-bands: a subcentromeric negalive band (I 2$)$ lollowed by four broad positive bands (13.15. 17. and 22) usually joined. thus giving the impression of one broald positive region.

Chromosome 20. Two regions. I1 G-bands: a subcentromeric positive band (12) and two positive bands ( 14 and 16 ) in the proximal half of the chromosome: a prominent positive band (2I) in the distal half is the main identifying feature of this chromosome; a negallive telomere. I I R-bands; a subcentromeric negaltive band (I2) and three positive bands (13,15. and 17) usually clustered in the proximal part of the chromosome; a broad negative band ( 21 ) lollowed by two minor terminal positive bands (22 and 24) are the main identifying features of this chromosome.

Chromosome 21. Two regions. II G-bands: Iwo subcen tromeric positive bands ( 12 and 14) close to each other. followed by two negative bands ( 15 and 17) separated by a small positive band (16) in the proximal part of the chromosome: two prominent positive bands ( 21 and 23) in the distal part; a negative telomere. I I Rbands: Iwo subcentromeric negative bands (II and 14) separated by a minor positive band (I 3) followed by 1 wo positive bands $\{15$ and 17) usually joined in to one broad band in the proximal hall of the chromosome: I wo wide negative bands ( 1 and 23) separated by a small positive band (22) and a prominen t lerminal positive band ( 24$)$ in the distal hall.

Chromosome 22. Two regions. 9 G-bands: similar to chromosome No, 23; a small subcentromeric positive band (1 2) followed by a broad negallive band (13) separated into two sub-bands (13.1 and 13.3) by a minor positive sub-band (13.2); I wo positive bands; one central (2I) and one subterminal (23); a negalive telomere. 7 R-bands: a small subcentromeric negalive band (I2) followed by a broald positive band (13): two central negallive bands ( 21 and 23) separated by a small positive band (2) $)$ a broad posilive telomerc.

Chromosomo 23. Two regions. I0 G-bands: similar to chromosome No. 22): a prominent subcentromeric positive band (I 2) followed by two negative bands ( 13 and 15) separated by a small positive band (14): two strong positive bands: one central (ㄴ) and onc distal (23): a positive telomere. 10 R-bands; a prominent subcentromeric negatlive band (12) lollowed by two positive bands ( 13 and 15 ) often joined into one broad band: a central positive band (22) close 10 band 15; a prominent subterminal positive band (24); the central negative band ( 21$)$ is less pronounced than the distal negative band (23); a negative telomere is usually not visible.

Chromosome 24. Two regions. 12 G-bands: a subcentromeric negaltive band (I2) followed by iwo positive bands (I3.1 and I3.3) often joined: a cent ral positive band (22): two small positive bands (24 and 26); a negative telomere. I() R-bands; a subcentromeric positive band (12) followed by a wide negative band (13); a small central positive band (21); iwo prominent positive bands (23 and 25) olten joined in the distal half of the chromosome; a positive telomere.

Chromosome 25. Two regions. 9 G-bands: a subcentromeric positive band (12) followed by two central positive bands ( 14 and 2l) often joined; a small positive band (23) in the distal hallf of the
Table 1. Similarities belween G-banding paticans of sheep and cattle chromosomes confismed by the Jouy-cn-fosas Conference

Shelj thromosomes numbered according 10 the recommendation of Long \{1985\}

Eyurvilem cille chromosomes numbered atiording 10 the

Reaktate devalumkindation

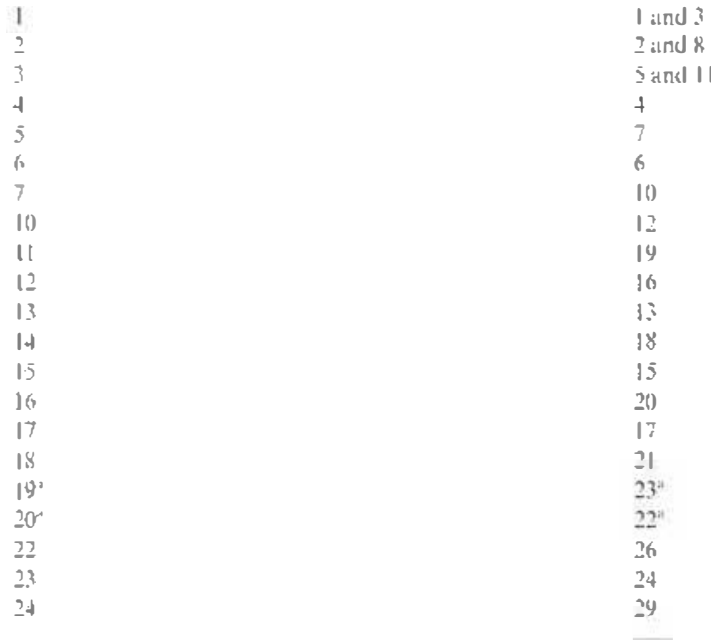

For shap chromosomes 19 and 20 . the equivalent caltle chromosomes ane diffefent from those listed in the Reading proceedings becuuse, in those proceedinys, the descriptions of

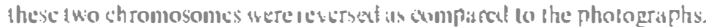

chromosome: a negalive telomere. 9 R-bands; a subcentromeric negative band (I2) followed by Iwo small positive bands ( 13 and $15)$ in the proximal half of the chromosome: Iwo prominent. usually joined, positive bands (22 and 24) in the distal hall, with 24 broader than 2 ?

Chomosome 26. Two regions. $7 \mathrm{G}$-bands; two prominent posilive bands: one subcentromeric (1 2) and one distal (2 2); negative telomere. $7 \mathbf{R}$-bands; a wide subcentromeric negative band and two prominent positive bands ( 21 and 23 ) sepaltaled by a negative band (22).

Chromosome 27. Two regions. I() G-bands; a subcentromeric negative band (I 2.1) followed by three positive bands (I2.2. 13 . and 21 ) joined in more contracted preparations; a broad terminal negative band (22) and a subtelomeric positive band (23); a negalive telomere. 8 R-bands: a pronounced subcentromeric positive band (I2) followed by three positive bands (14.22. and 24) which tend to be joined in more contracted preparations.

( hromosomc 28 . One region. $9 \mathrm{G}$-bands: al subcentromeric posilive band (I 2), two prominent central positive bands ( 44 and I6): a small subtelomeric posilive band (18). 9 R-bands; three positive bands: one proximal (13). one central $\{15)$ and one prominent subterminal (17); a positive telomere.

Chromosome 29. One region. 9 G-bands: Iwo proximal positive bands ( I I and 14) often joined; a central positive band (16): a small subterminal positive band (18): a negaltive telomere 9 R-bands; Iwo small positive bands ( 13 and 15$)$ in the proximal hall of the 

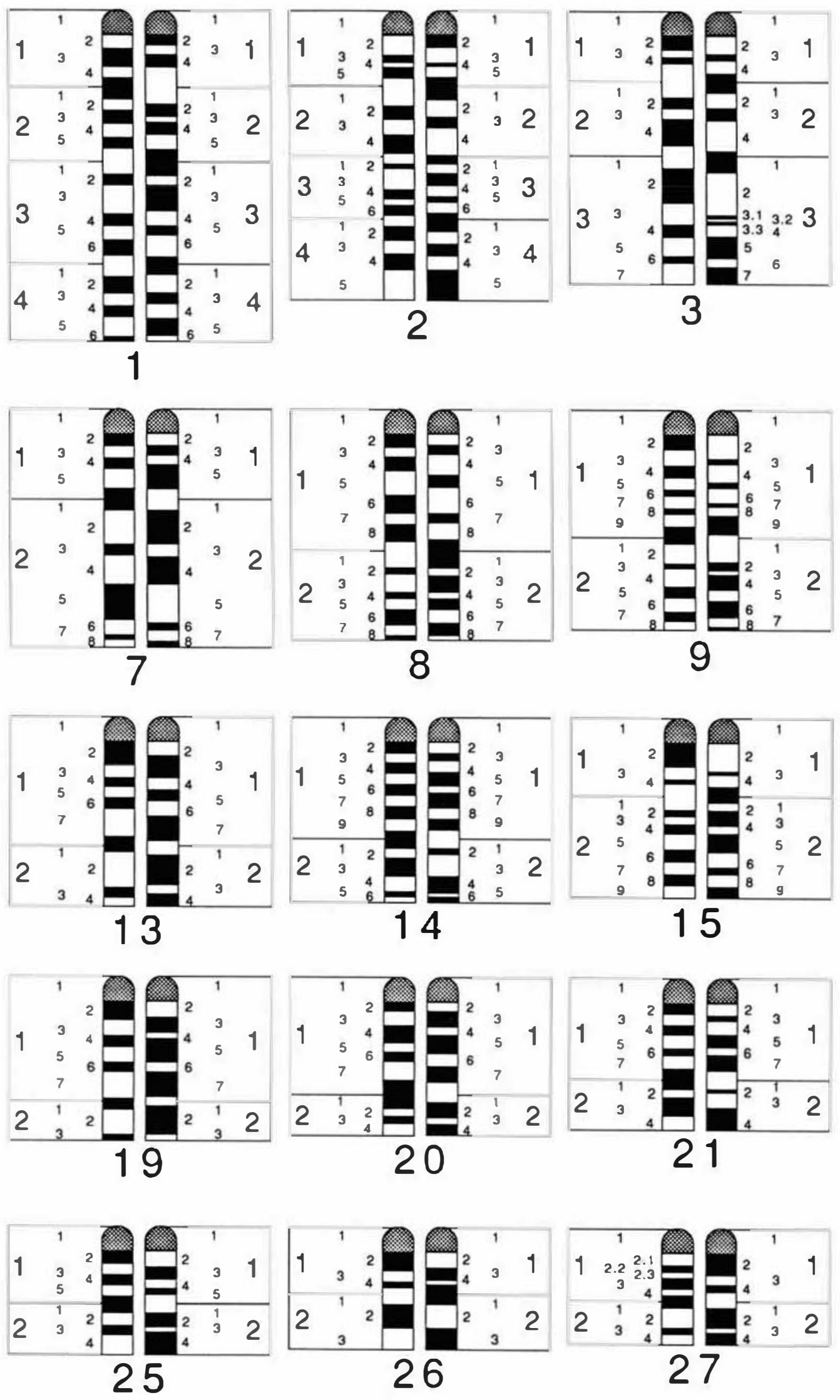

lijg. 5. Diagrammatic representation of G-bands (left) and R-bands (right) of cattle chromosomes. 

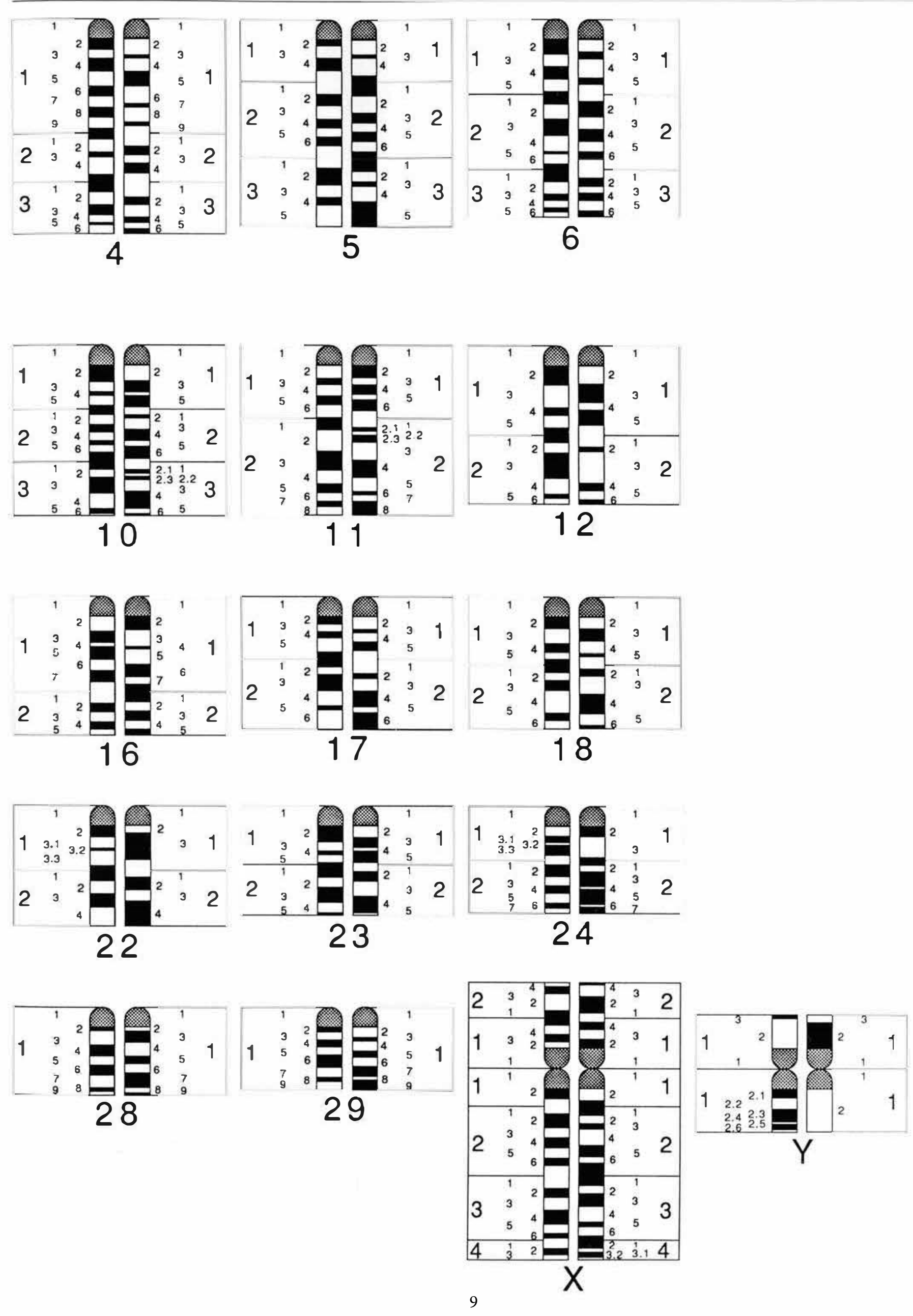


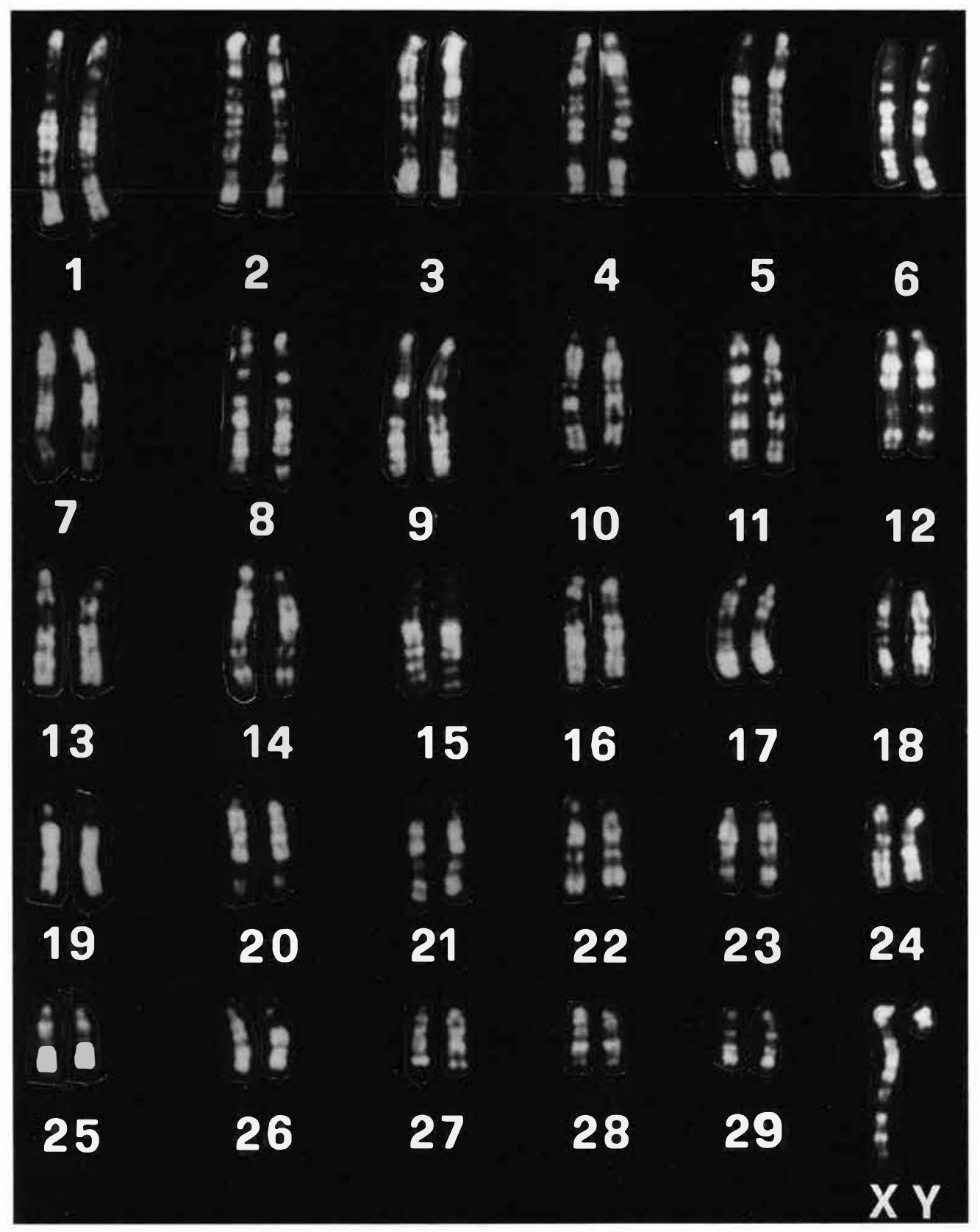

Fig. 6. Standard RBA-banded goal karyotype. (Courtesy of D. Di Berardino and of Journal of Heredily 78:225-230. 1987: copyright 1987 by the American Genctics Associalion.) chromosome and I wo positive bands (I 7 and 19) of the same size and usually joined in more contracted preparations in the distal hall.

Chromossome $X p$. Two regions. $8 \mathrm{G}$-bands; a central positive band (ㄴ) lollowed by a negative band (2ㄱ) and a small subtelomeric positive band (23): a negative telomere. 8 R-bands: a distal positive band (22); a smail subtelomeric negative band (23); a positive telomere.

Chromosome $X_{q}$. Four regions. 17 G-bands; a central broad negalive band (31): lour positive bands (12. 22, 24. and 26) in the proximal half of $\mathrm{Xq}$ and lour positive bands (32, 34, 36, and 42) in the distal hall of $\mathrm{Xq}$; a negative telomere. 18 R-bands; a cluster of three positive bands (25. 31, and 33) at the center of $\mathrm{Xq}$; a large negalive band (24) above this cluster and two negative bands ( 34 and 36) separated by a small positive band (35) below this cluster: two terminal positive bands ( 4 l and 43 . I) olien joined; a negative telomere.

Chromosome Yp. One region. $3 \mathrm{G}$-bands; enlirely negalive with a positive telomere. $\mathbf{3} \mathbf{R}$-bands; entirely positive with a negative telomere not always visible.

Chromosome $\gamma_{4}$. One region. 7 G-bands; three positive bands ( I $2.1,12.3,12.5$ ), with 12.3 being more pronounced. No R-bands; $R$ banding reveals an entirely pale $\mathrm{Yq}$.

\section{Goat and Sheep}

For these two species less information was available as a basis for establishing the standards than for cattle. particularly for the G-bands, which limited the conclusions. 


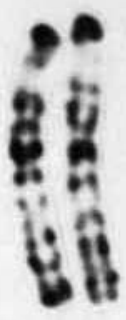

1

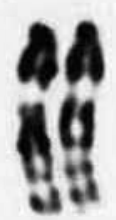

7

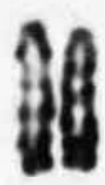

13

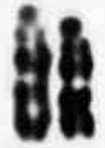

19

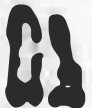

25

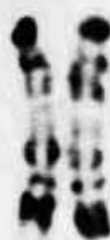

2

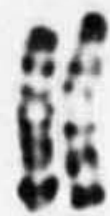

8

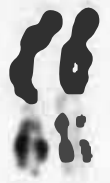

14

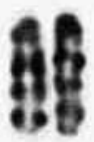

20

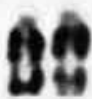

26

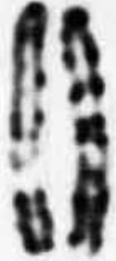

3

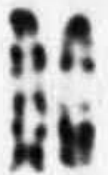

9

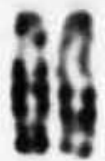

15

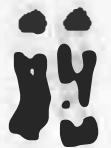

21

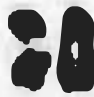

27

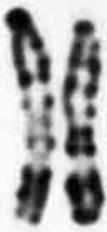

4

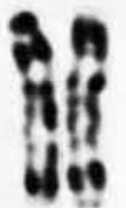

10

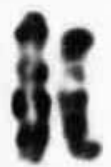

16

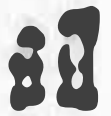

22

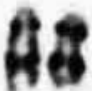

28

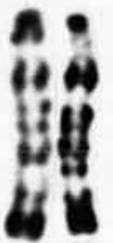

5

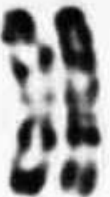

11

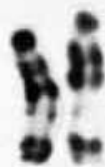

12

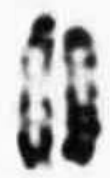

17
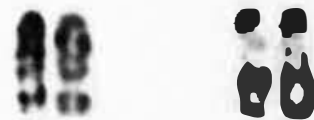

23

24

Fig. 7. Standard RBG-banded goal karyolype. (Courlesv of H. Hayes.)

\section{Goat (Capra hircus)}

Coordinator: H. Hayes

Contributors: H. Hayes, D. Di Berardino; M.B. Lioi, D. Mallassino, R. Hediger. H. R. Jung, and G. Stranzinger

Examinations of the G-band palterns of goall and cattle chromosomes led to the same conclusion as that reached all Reading. i.e.. that G-banded callle and goal chromosomes resemble each other closely with the exccption of chromosomes 9. the X. and the $Y$. However. since insufficient informaltion was alvailable for the goall, it wals agreed to not present a new GTG-banded kalryolype and to not make schemaltic representations.

Comparison of the R-band patterns (RBA and RBG) of goatt and calltle chromosomes contirmed their similarity except lor chromosomes 9 , the $X$, and the $Y$. A precise description of the differences between the balnd patterns of goal and caltle chromosomes 9 could not be algreed upon.

The extensive similarity between the karyotypes of goat and cattle made it possible to establish a standard karyotype for Rbanded goat chromosomes which follows exactly the classification and the numbering of R-banded cattle chromosomes based. as discussed above, on the Reading standard. It was decided 10 adopt the land marksestablished for callle chromosomes for the R-banded goat chromosomes.

Figures 6 and 7 present standaard RBA- and RBG-banded katryotypes, respectively, lor the goilt. 
Fig. 8. Standard Ri3A-bausded shecp karyolype.

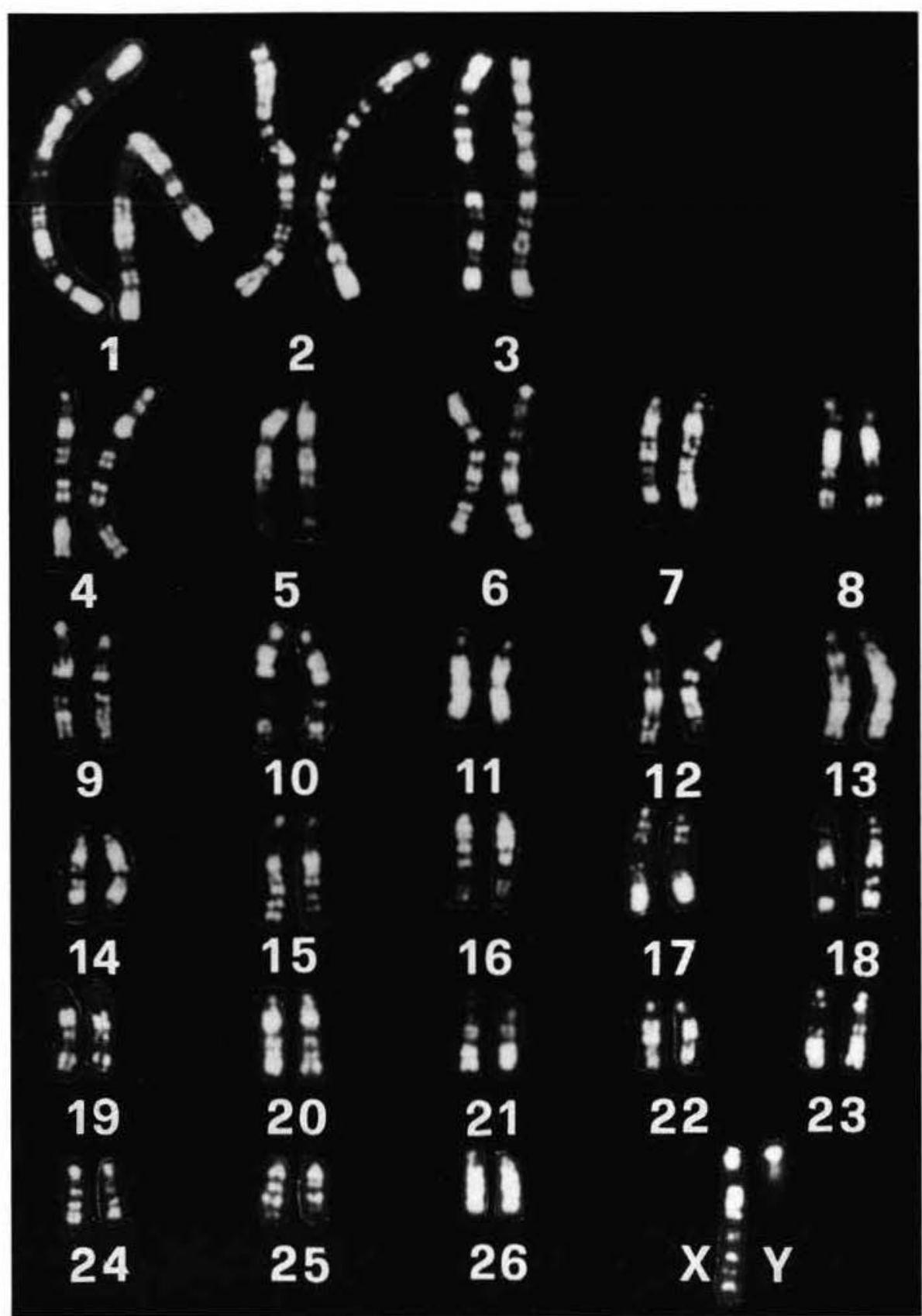
(Courtesy of D. Di Berardinu.)

\section{Sheep (Oris urie's)}

\section{Coordinator: S. Long}

Contributors: S. Long. H. Hayes. D. Di Berardino. M. B. Lioi. D. Mallassino. R. Hediger. H. R. Jung and G. Stranzinger

As was noted. al karyolype system was recommended lor sheep by Long (1985) after the Reading Conference. Since some confusion arose because in the proceedings of the Reading Conference the descriptions of G-banded chromosomes and the corresponding pholographs were interchanged in the calse of sheep chromosomes 8 and 9 , als well as 19 and 2() , it was decided to use only the karyotype of l.ong (1985). as a basis for the one presented here. As was outlined in the Reading Conference proceedings. many similarities exist between the G-band palterns of sheep and callte chromosomes which were conlirmed during the discussions at the Jouy-en-Josils Conference for the chromosomes listed in Table 1 .

The relationship is less clear lor sheep chromosomes 8, 9. 21 . 25. and 26 becaluse of the limited amount of informaltion a vailable for sheep G.banded chromosomes.

Becaluse the amount of informaltion on the kasyotype of the sheep is still limited. it was decided to not present a scheme for this species. Instead, it is suggested that the G-band system recommended by Long ( 1985) be used until further results are obtained. On the other hand. comparison of R-banded karyotypes of sheep and callte showed that the patterns of these two species are very 

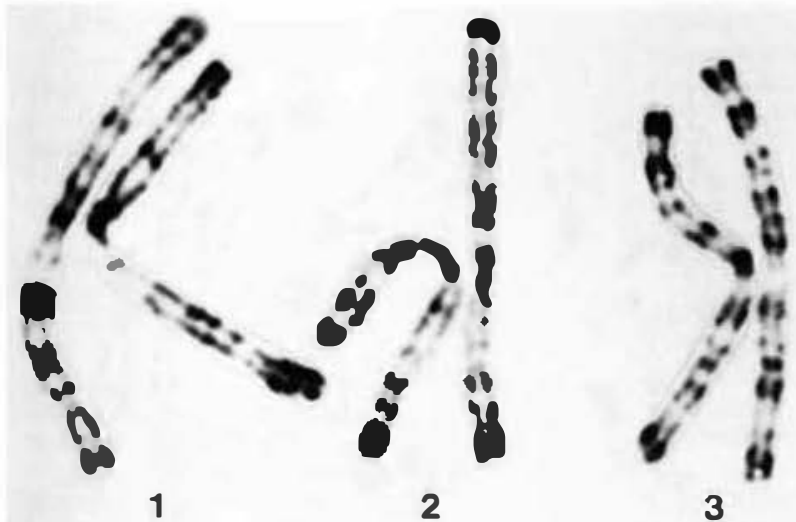

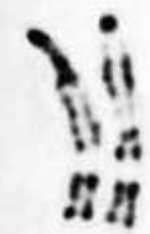

4

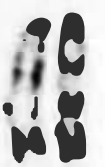

9

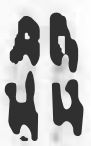

14

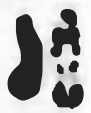

19

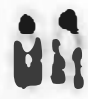

24

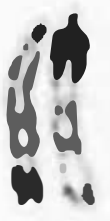

5

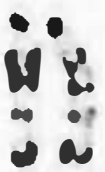

10
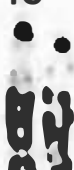

15

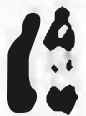

20

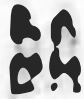

25

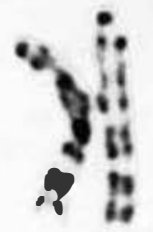

6

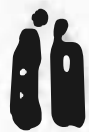

11

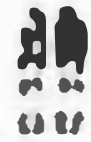

16

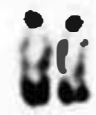

21

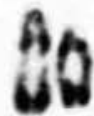

26

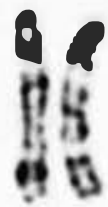

7

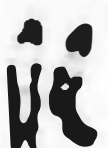

12
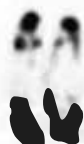

17

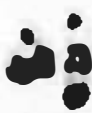

22

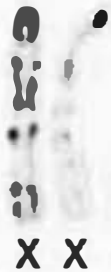

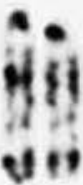

8

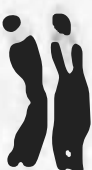

13

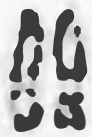

18

Fig. 9. Standard RBG-banded sheep karyolype. ICourtesy of $\mathrm{H}$. Jaycs.) similar and that each sheep chromosome was similar to one or two caltle chromosomes, depending on whether it is metacentric or not. except for the sex chromosomes.

As for caltle and goall. this relationship has been independently confirmed by two laboratories using two R-banding methods (RBA and RBG).

The same diff observed between callte and goall chromosomes 9 was found between callle and sheep chromosomes 9 . However. since there is a good correlation between the G-band palterns of cattle and sheep and the R-band patterns of cattle and sheep. it is possible by inference to correlate $G$ - and $R$-band pallterns in sheep and to establish and standard R-banded karyolype lor sheep. Figures 8 and y sepresent such RBA- and RBC-banded karyotypes, respectively.

\section{Comparison of R-band patterns of cattle, goat, and sheep}

The comparison of the karyolypes of the three main Bovidae species confirmed the extensive similarity of their euchromaltin. This is illustratled by the pholographic montage combining RBGbanded chromosomes of callle. goalt. and sheep in lïg. 10. As wals indicalled in the Realding proceedings $(1980)$. this provides further evidence for a close evolutionary relationship between these three species. but maly not imply genetic homology. 

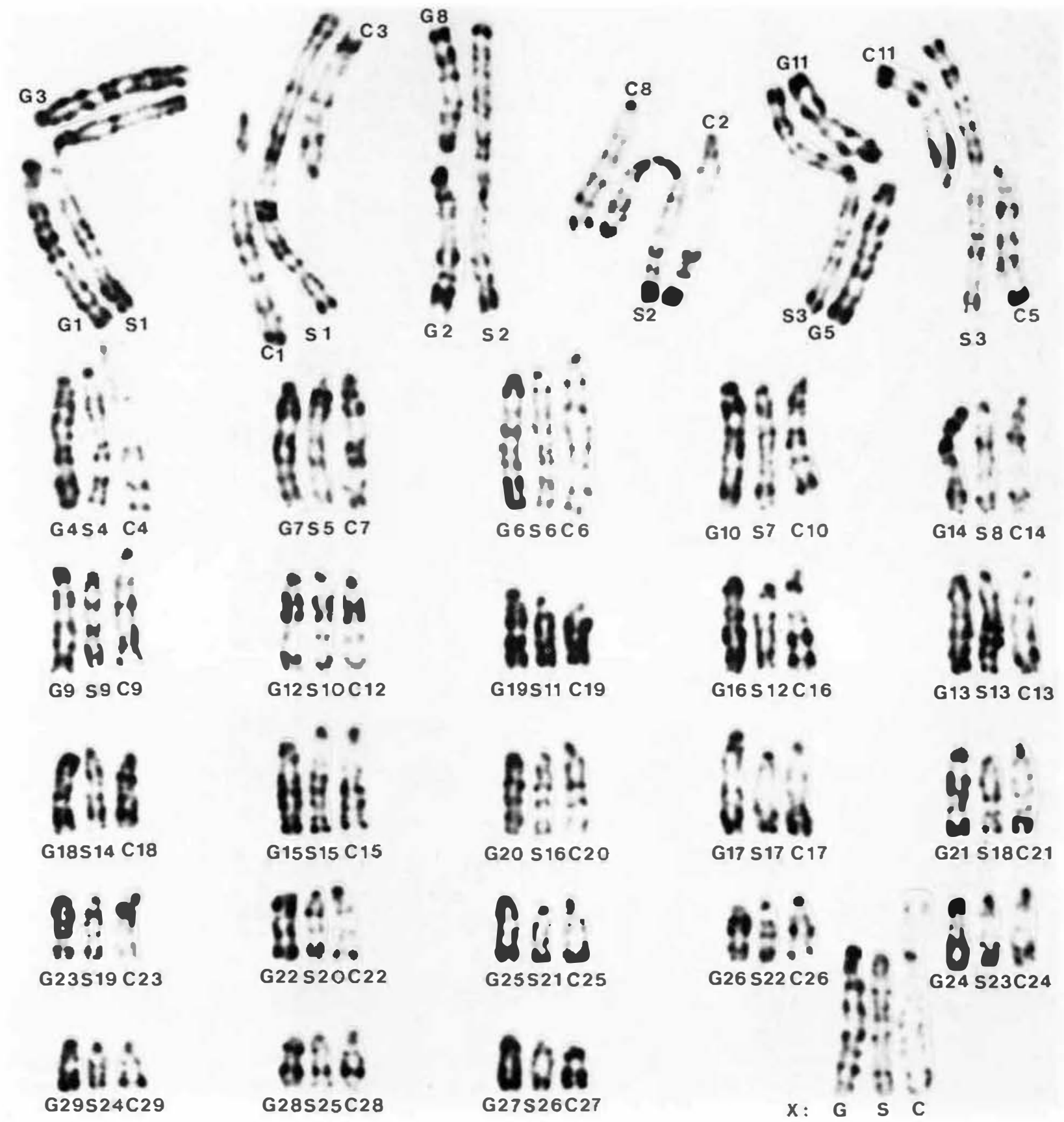

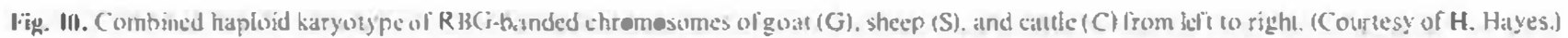

Ref erences

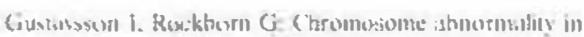

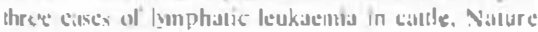

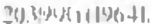

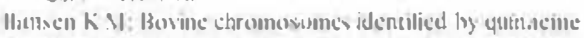

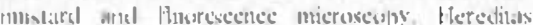

711:225 $2.1+119731$.

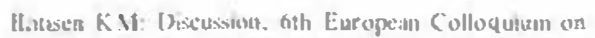

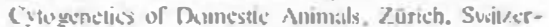
hand $(19 \times+)$

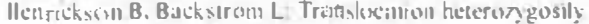
in a bour. Heredisas 52:166 170)(16) (n+t).

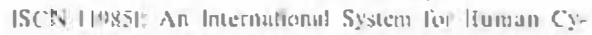

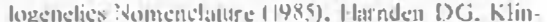
petr H Picds)।S Karger. Bakel New Yosk 1985).
Long S: Stalldard nomencititure for the Gi-band kisryolypu

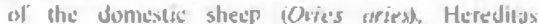
[() $3: \mid 10 \leq-17011985$,

Resading (onferencel $\mid y \times())$ : traxicedings of the first internil-

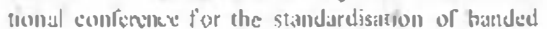
kargetypes of dounestic animals. Reading. England ([376) ford (CE. Pollock DL. (justavsson I leds). Ilexeditas $2: 1+5-11321(480)$. 